\title{
Smart Buildings in Italy, some BIM designed examples
}

\begin{abstract}
The real value of BIM, as a method, is partially undiscovered and require deeper understanding of what real potentialities are and how to take advantage of them in the professional activities. More than ever before the collaboration between engineers, architects and technicians is promoted thanks to BIM. On top of this, the construction industry has realized that the main weakness for decades were the lack of effective communication through reliable and timely channels. Naming BIM, the entire design process should be revised, because we should finally accept that the cooperation, communications and sharing are the seminal elements of the success. This paper, starting with these premise, will present and analyze some good examples of BIM designed projects realised recently in Italy, as the Unicredit Pavilion in Milan by Architetto Michele De Lucchi and the Forti HQ in Pisa by ATIproject that marge smart building processes with environmental targets and a new vision for the urban fabric quality.
\end{abstract}

Keywords: BIM, Design Process, Case study, Italy

When dealing with Building Information Modelling, a concept introduced with the birth of the modern computers and machine drawing in the 60's of last Century led by Ivan Sutherland at MIT, we still think about programs that enable us to draw our projects through newer software programs. Furthermore, many of us consider BIM as an innovation that should be used because of the advantages widely publicized in the prospects of the software companies that produce software like Tekla, Archicad or Revit, just to name few.

Perhaps, the real value of BIM, as a method is partially undiscovered and requires deeper understanding of what are its real potentialities and how to take advantage of them in the professional activities.

More than ever before the collaboration between engineers, architects and technicians is promoted thanks to BIM. On top of this, the construction industry has realized that the main weakness for decades has been the lack of effective communication through reliable and timely channels.

Having in mind the Abernathy-Utterback Model for the innovation dynamics, the field of Building Information Modelling is represented in ill. 1 through the characteristic curves of product and process innovation. As we can notice, products as Archicad, Revit and Tekla occupy more than $40 \%$ of the software market for computer aided design and they have a well-established user interface which overall maintains the same philosophy embedded in BIM. Since the methodology incorporated in these software is considered stable, we assume that many companies are seeking to innovate in the field of organizational processes that are broadly defined or not defined at all. Past surveys on one of the most developed markets which is the North American one, confirms the abovementioned statement: BIM is considered as a mature methodology to be applied among vast majority of players in the field of architecture, engineering and constructions.

Jointly to the latter, the Gartner's Hype curve (ill. 2) explains even better in which phase the Building Information Modelling is in respect to the AEC industry expectations translated in visibility on the model. Starting from the CAD in the $80^{\prime}$ and the dot-com boom in the beginning of the 2000s, each innovation like BIM follows quiet the same characteristic trajectory described by Gartner after many observations and analyses.

Since BIM adoption in each single country has reached different levels, a summarized consideration of the international AEC field could be done using the hype curve. It holds realities ranging from advanced use in USA (ill. 3), Australia and Hong Kong to basic applications (Germany, France) or almost no-adoption (Italy and Eastern Europe). The reasons for that are, as always, political, cultural and sectorial and should be analysed apart.

Before making an investment in this kind of technology we should know that there is not just a unique piece of software behind the BIM concept. Thus, the entire design process should be revised, because it should be finally accepted that cooperation, communications and sharing are the seminal elements of success. Seeking to obtain all this, a strategy should be identified that further entail broadly our ideas for the future.

The first and most important part of the BIM paradigm is "us", stated as personal skills and 


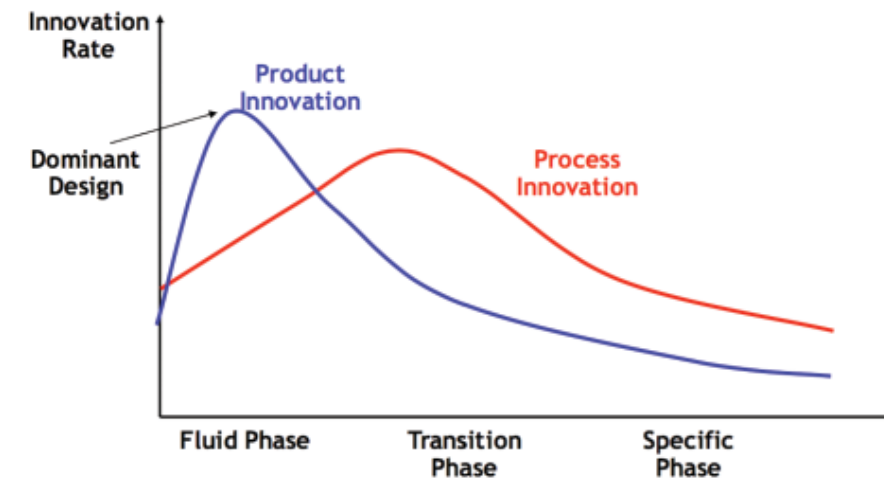

ill. 1. Generic Abernathy-Utterback model for Innovation Dynamics. Credits
Adner, R., \& L Levinthal, D. (2001)

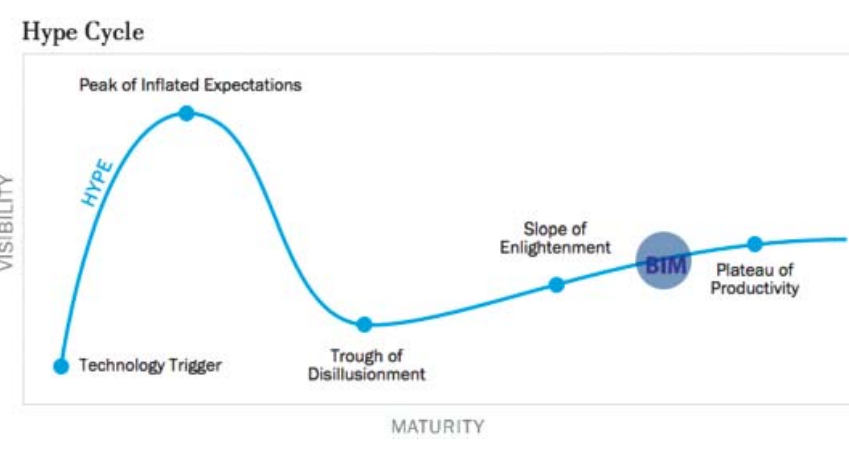

II. 2: Gartner's Hype Curve of BIM. Re-elaboration by D. Duchev

\section{The percentage of companies in 2007, to $49 \%$ in 2009, and to $71 \%$ in 2012. For the first time ever, more contractors are using BIM}

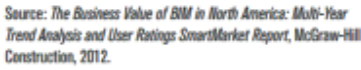

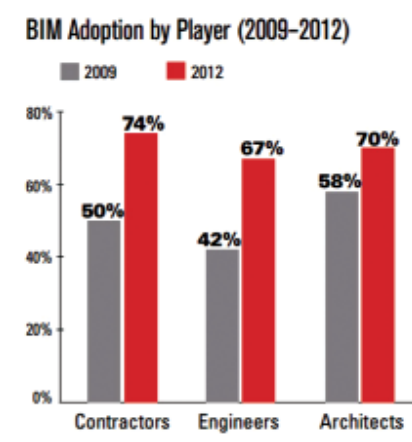

ill. 3: Rate of adoption of BIM in the US AEC sector. Credits MCGraw-Hill Con-

the willingness to achieve great results with intelligent and state of the art tools that at the same time enhance creativity. as professionals with other professionals and deciding what we want to deliver to our clients and what our customers appreciate the most.

Further, the openness is not a threat. Publishing your plan timely with sufficient details for the right purpose is important for the stakeholders of the project. Someone could argue that in this way the project become an easy candidate to be copied or hijacked. But beside the latter, we should know that some aspects cannot be copied such as talent, internal organizational structure and culture of the design team and the competences that stand behind the project. Drawings are the final manifestation and all the aspects mentioned above remain encrypted into the final project. There is no key for the external observer through which these artefacts are going to be unlocked.

Second most important pillar we already mentioned is the internal organization and processes in a team or organization. Many times, the work of the architects is thought to be turbulent, full of ambiguities and apparently disordered. One of the crucial elements that we should accept is to work smarter and not harder. We should just leave all prejudices about the profession of the architect (and all the other kind of professionals) and (and all the is possible and we just try to build soryth is possible and we just try to build something mom is one the steps the who an is one of the steps that we should undertake. On other hand, distributing and defining the roles, appointing responsibility to each person, requirements for data drops, deliverables and creation of storage containers, are all administrative and organizational tasks to be defined by the team members or managers. Fortunately, differently from the past all these tasks have their cyber equivalent living in the digital world and great part of this could be done via the tools offered by BIM and by mainstream ICT. Translating the physical world into a digital one is creating the so-called cyber-physical system, where each complex system that we maintain become even a digital one, with all advantages and disadvantages we can imagine.

Third, before the transfer of even one byte of our work into the new paradigm, we should evaluate professionally and clearly the flaw of competences and what we need to learn before undertaking our new journey towards BIM Thus, skill endowment of the profession B much more important of the both the software and the organizational scheme. To smpor the professions, strong technologits chould be developed through conthuous should be developed through conthuous seminar, workshops that are developed on

Lasly, the program or the set of programs, th support the BIM method should be selected.

This selection should consider:

- The characteristics of the computers an

availability of funds for upgrades;

How the organization is built, and what type of professionals reside in it;

How the present and potential partners of the team are endowed;

The average complexity of the projects developed by the teams

What are the deliverables required by law and by the customers?
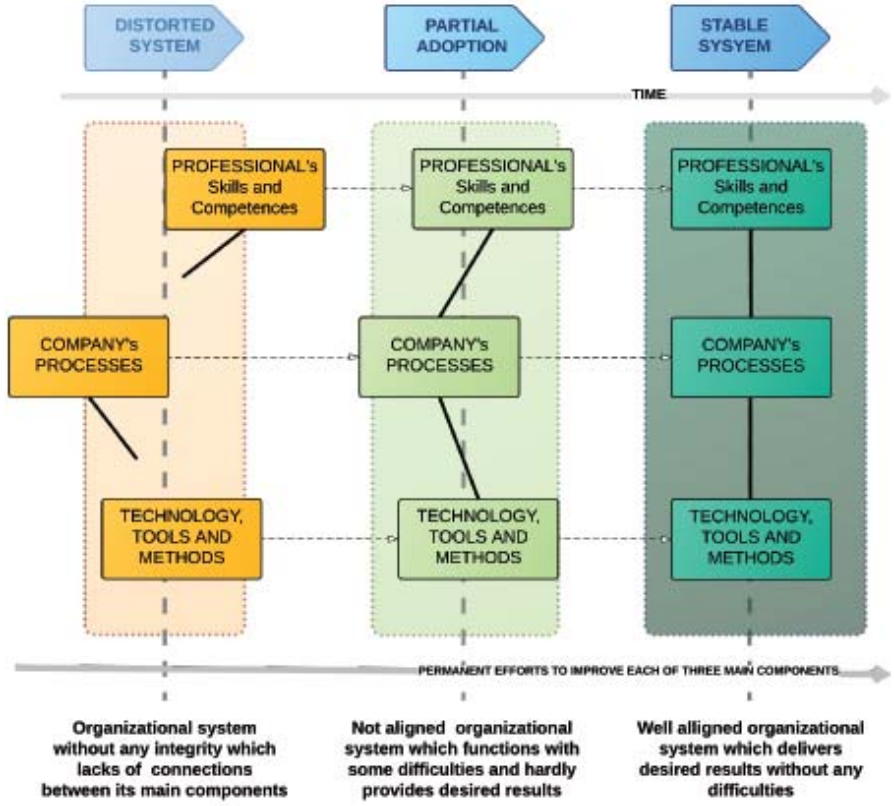

ill. 4: General scheme of Alignment of the three main elements driving BIM.
(Elaboration by D. Duchev)

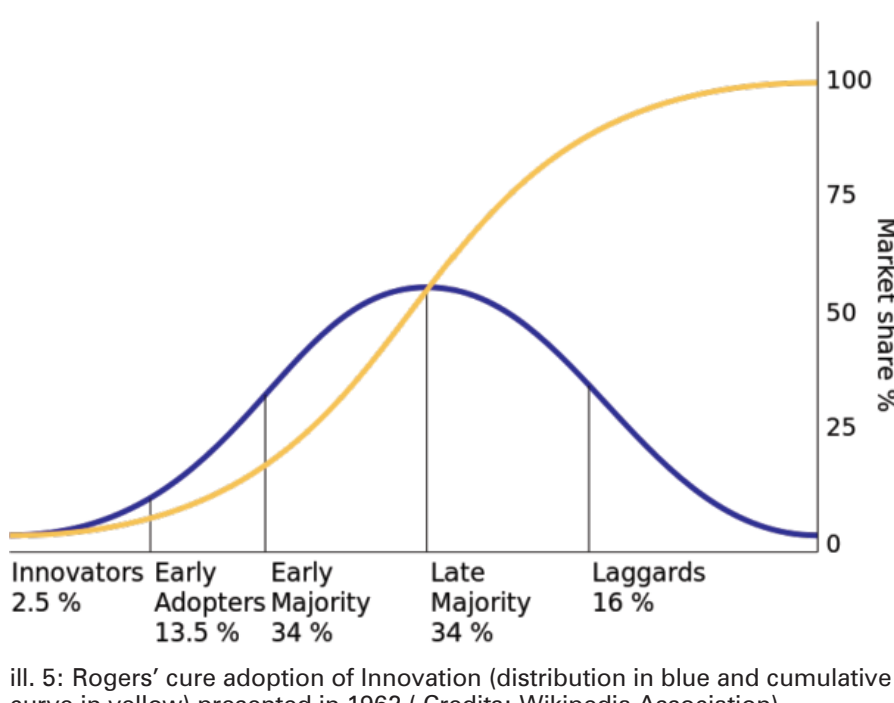

ill. 5: Rogers' cure adoption of Innovation (distribution in blue and cun
curve in yellow) presented in 1962 . ( Credits: Wikipedia Association)

There are different fields in which the outcomes Building Information Model will provide as output, depending on the diverse work-teams. These outputs can be classified according the following respective disciplines as Urban planning, Structural Design and Engineering, Installations (HVAC, electrical Plumbing), Architecture, Energy Management and Energy Efficiency, Life Cycle Assessment, Life Cycle Costing, and Adaptive and Dynamic Computational Design.

Furthermore, existing pre-concepts that imply rigid separation of different disciplines are going to be changed adopting this model, thriving for more holistic and comprehensive frathis model, thriving for more holistic and comprehensive framanaged in integrated and organic way through cooperative and flatter networks of professional subjects acting alone or in formal organizations (ill. 4).
Rate of adoption can be better explained through Roger's adoption curve introduced on ill. 5 which explains how an innovation is adopted in certain customer environment. Here, it can be assumed that the AEC sector is virtually divided into five groups having different propensity to absorb innovation and the Roger's model fits well in this conceptual explanation. At the same time connected to this, we can apply real empirical example depicted briefly by real empirical example how what are the benefits for the first two row

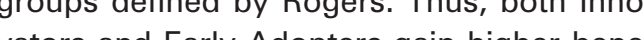
fits in terms of $\mathrm{RO} 1$ having adoped $\mathrm{BM}$ as part of its business. The sudy presen as part of its business. The study presented by haff of the highy-engaged organizaws that half of the highly-engaged organizations reach a ROl higher than $25 \%$. Afterwards, we and having the un being committed to BIM and having the understanding that it is worth in long term, could generate efficiencies for the organization, supporting at the same time creativity, and increasing customer value. To support the latter, three examples in the building construction and architecture in Italy are presented here.

These three examples provide an insight about how organizations different by structure, size and ownership can interpret and adopt $\mathrm{BIM}$, and which are the functionalities they value most.

\section{ill. 6: ROI related to the level of BIM engagement revealed}

Very Positive ROI on BIM (Over 25\%)

Moderately Positive ROI on BIM (1\% to $25 \%$ )

Negative and Break-Even ROI on BIM

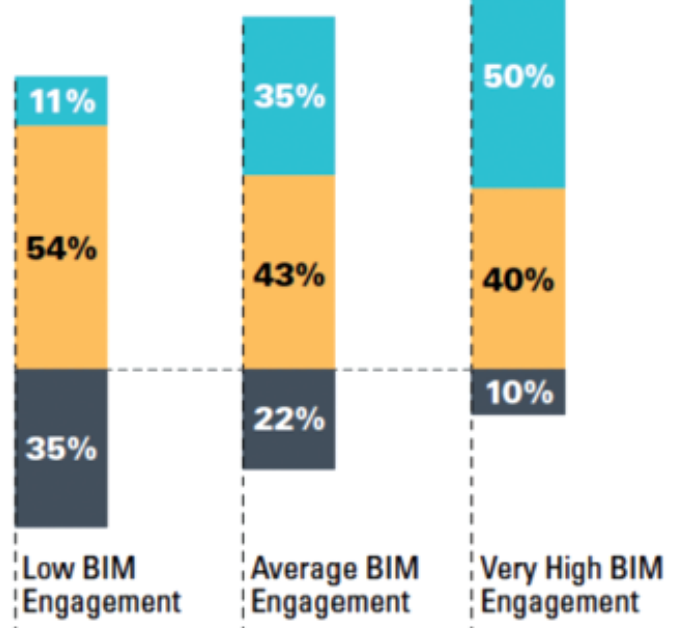




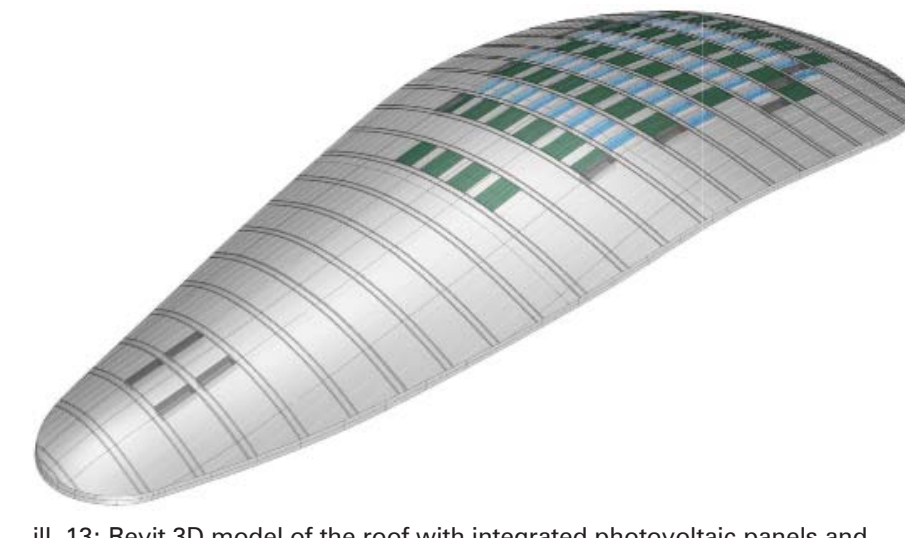

ill. 13: Revit 3D model of the roof with integ
skylight windows. Credits MDL architects

photovoltaic panels, curved metal sheets and integrated roof eaves whose drawings have been obtained directly from the pavilion's BIM model and consequently transferred into the production plan, where thy have been accurately manufactured to fit precisely in during the installation phase.

Most importantly, the pefect matching between the concrete core structure, the timber frame external structure, and the HVAC plants integrated into the building have been facilitated by the $3 \mathrm{D}$ building information shared model.

Additionally, all parties involved in this project stated that Building Information Modelling delivered the desired results on time, permitting the opening of the complex in parallel with the EXPO Milan 2015 events and improving on one hand the building process and on other hand the building's overall performance.

Milano Strozzi Street Public School (ATlproject, on going) Looking at Milan as one of the most vital places in Europe it can be said that the development and improvement of new education facilities is under way. Starting from one of the most advanced universities like Politecnico di Milano, where a Sustainable Campus program is promoted, passing through the state of the art kindergarten embedded in the Unicredit Pavilion, we describe here the project for a public school that has recently received State and Regional funding

ill. 14: Milan Strozzi School model REVIT rendering. (Credits: courtesy ATlproject)

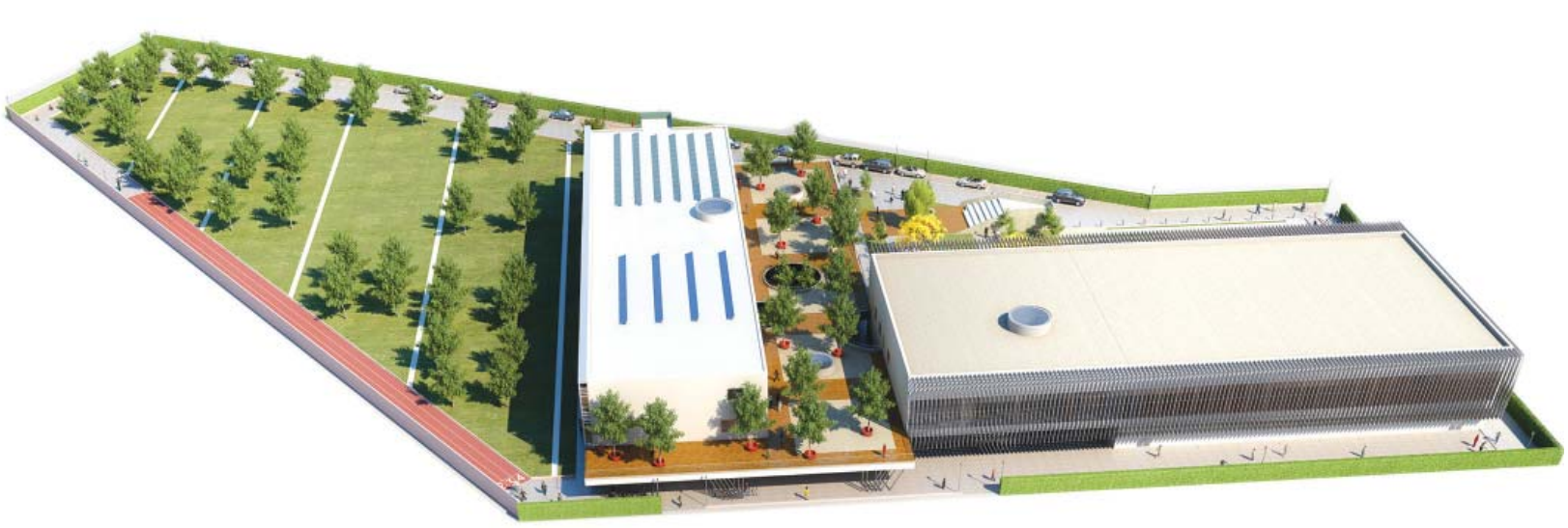

thanks to a requalification and innovation enhancing plan that has the aim to strengthen the sustainable and equitable development of one of the largest metropolitan areas in Italy. The Strozzi Public School is one of them. Once completed, it will meet highest environmenta and energy performance standard reaching LEED Platinum standards and will provide flexible and well-designed study spaces.

Architecture Studio ATIproject is the winner of the public bid organized by the City of $\mathrm{Mi}$ lan. The studio provided an integrated dethis method of design could be the only new this method of design could be the only new new way to rethink the approach from larger brown field recovering projects urban requalification scale. the School has a three-storeys main building which hosts classrooms, a library, and offices, along with a second building dedicated to sport activities, special events and a canteen. Both buildings, made by timber frames, are surrounded by green areas, and a vegetable garden. The Strozzi School is innovative both for its social and educative characteristics and for the environmental targets that would like to accomplish, and has been designed with one of the most innovative BIM tools as Revit. Looking at the ATlproject's design we discover that the bioclimatic approach is accompanying and integrated all along the project phases, merging with all the disciplines as architecture, structural engineering, and $\mathrm{HVAC}$ renewable energy sources plumbing and trical systems plants.

Furthermore, all these disciplines have given the birth to an integrated and fully function 3D model full of all releant dat that chaDacterize each single element to be bult. For prefabication srocess purposes, BIM offers sign approach provided an integrated de-

Having started the construction in April 2017,

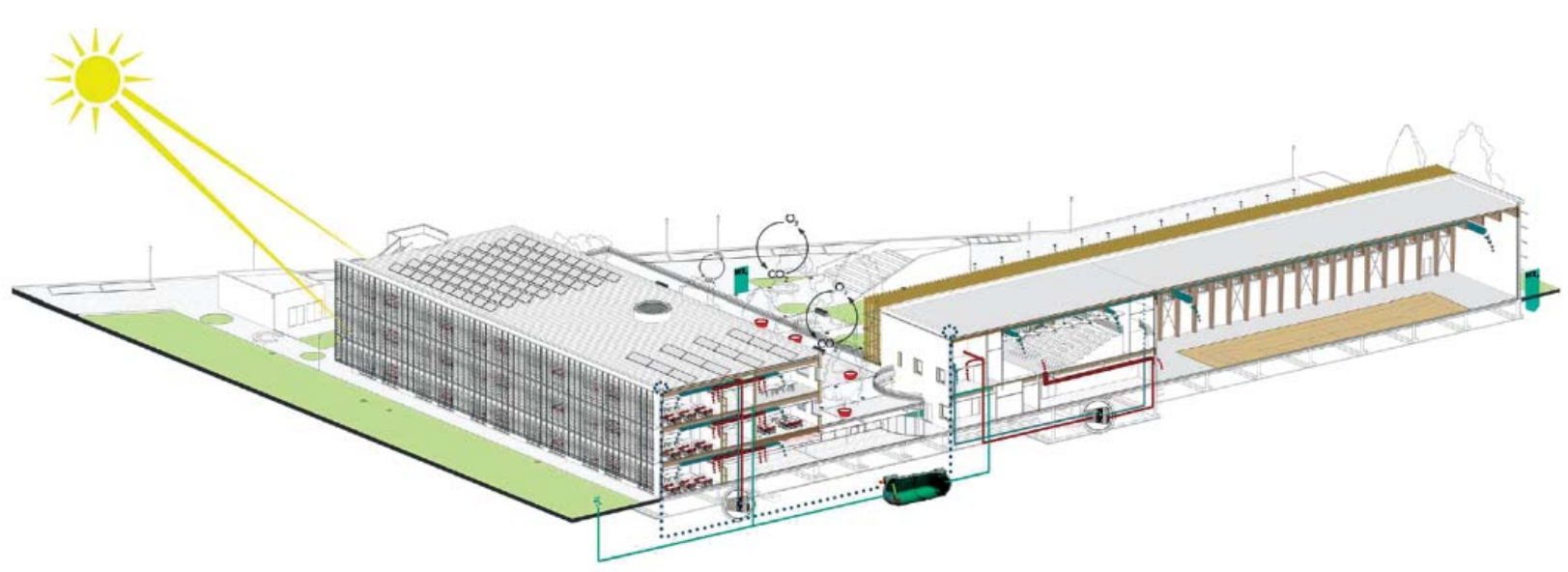

ill. 15: Bioclimatic analysis with the help of Revit 3D model. (Credits: courtesy ATIproject)

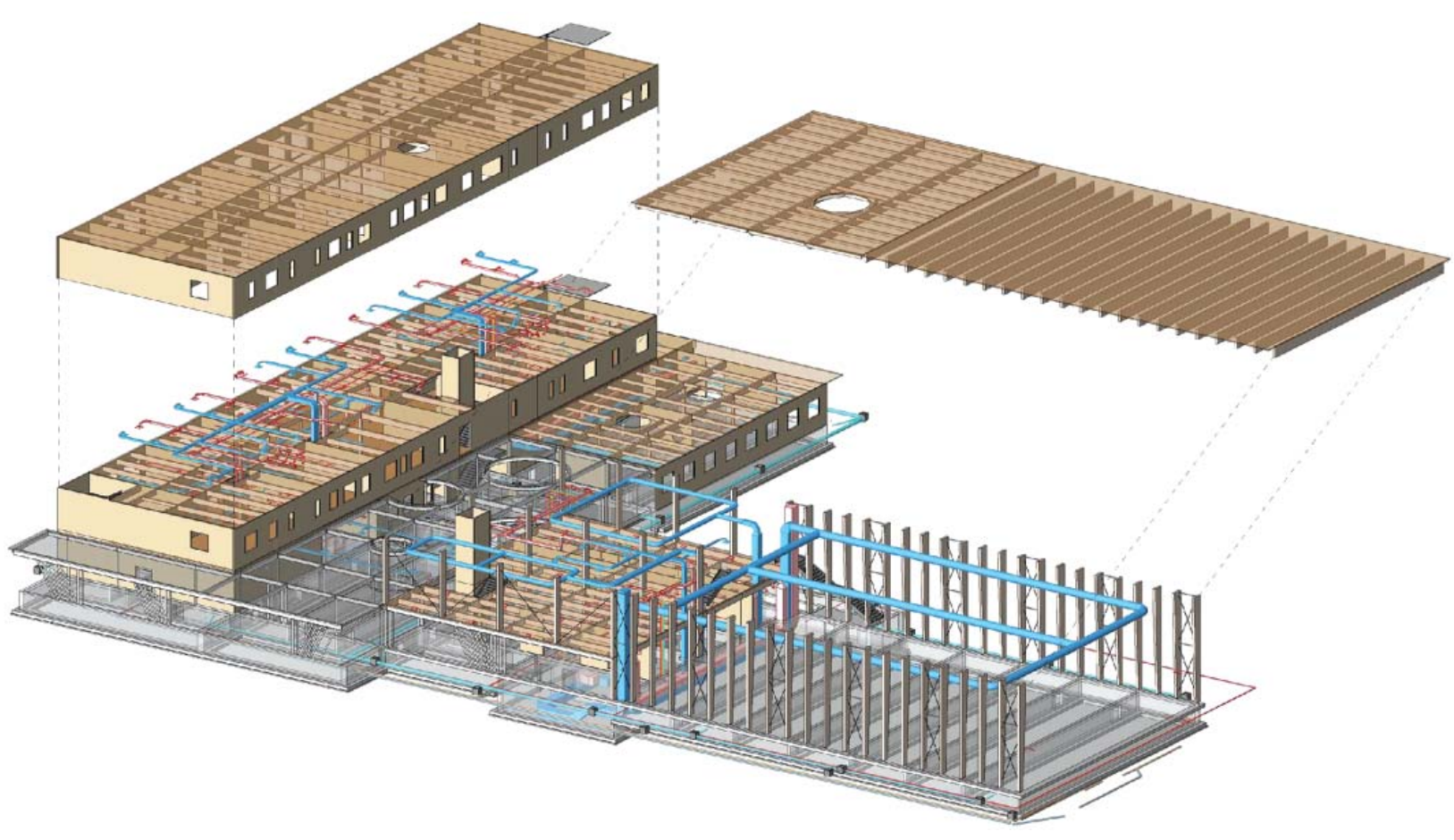

ill. 16: Explo
ATlproject)

great definition of each construction element, so the prefab procedure is facilitated by the continuous flow of executive drawings useful to the producers of timber beams, colum ns, partition walls and ducts that have to be manufactured off site. In other words, the prefabrication methods together with this new method of designing provided by an advanced software, jointed to a transparent collaboration philosophy including the participation element, have brought ATIproject to a successful realization, that will increase the value of the town, as a whole.

\section{Forti Office building (ATlproject, 2016)}

Unlike two previous examples, where big institutional clients lead extensive projects within the urbanized area of Milan here we present another good example showing how extensive and versatile can be BIM in different environments.
The private company Forti Holding Spa asked in 2013 to AT/project to design its new headquarter in the rural area of Pizza, located in Montacchiello (Pisa Province, Tuscany). The explicit request of the client was to pay great attention to environmental sustainability an the building's energy consumption along with all the other needs related to an office representative building.

Even if both the concrete cast-in-place load bearing structure and the prefabricated stee framing have been managed through traditional design processes, at some point these data have found a common point for exchange between different disciplines using different design tools, supporting in this way the further 


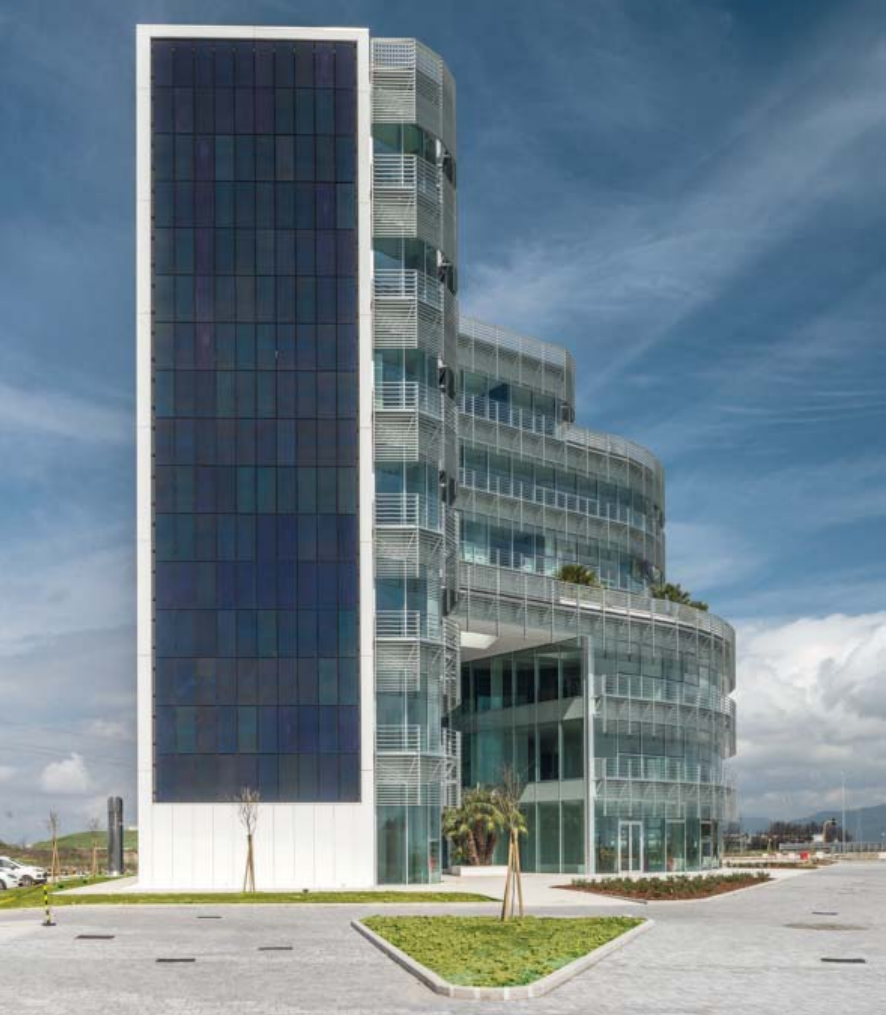

development of the other sub-routines. How happened in the Strozzi School design, also for this project BIM has been used as a tool through which has been designed the glazing façade and the HVAC system in order to fulfil the client's requests.

Notably, the use of BIM helped the designers to determine and simulate the behaviour of the building under different

\section{ill. 19: representation on top of Revit $3 \mathrm{D}$ section, of the management of ther-
mal equilibrium of the building during winter. (Credits: courtesy ATIproject)}

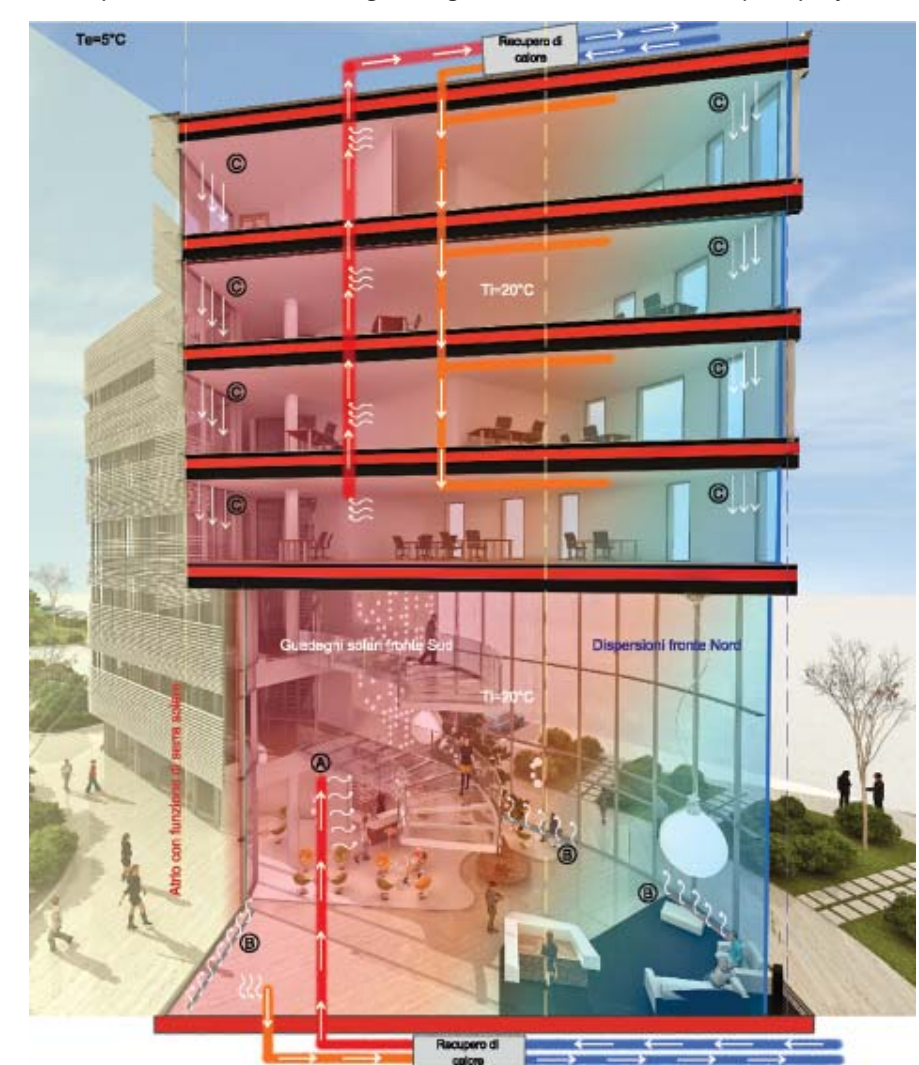

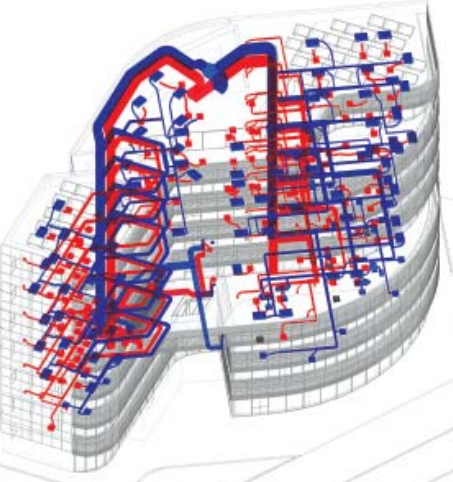

ill. 17: Forti holding headquarter south façade characteripower needs. (Credits: Photo by Irene Taddei, electric ATIproject).

ill. 18: Heating and cooling ducts connected to ground thermal pumps modelled with Revit MEP on the
BIM virtual building. (Credits: courtesy ATIproject)

weather conditions in addition to bioclima tic design of the facade conformation, which ices, which have been made taking count of all these parame ters to obtain an optimat and easier to build up HVAC configuration.

Looking at this 2013 project developed by this young Pisa's company, the implementing of new design tools and methods like BIM appears as a natural flow. In facts, BIM should be adopted gradually, along with the en hancement of the skills and knowledge of the designing team. Lastly, the modularity and the interoperability of BIM tools allow such gradual approaches in the adoption even though the full potentialities of the tool are always available. In fact, such a dynamic can be observed following the application of BIM on these two assignments, one dating 2013 and the other 2016 where ATIproject shows one side to be 'grown-up' capability and on the other how smart cities require well prepared designer and builders that transform concepts into reality.

In the final analysis, all these three Italian examples provide to demonstrate how integrated design system can be applied by different actors in different contexts. It can be sid tha BIM method covers a brod cange of phases (ill. 20) starting from the planning and consest design ariving to the papetion maintente there is an evidence that the complexity of use there is an evidence that the complexity of use BIM depends on the development of the

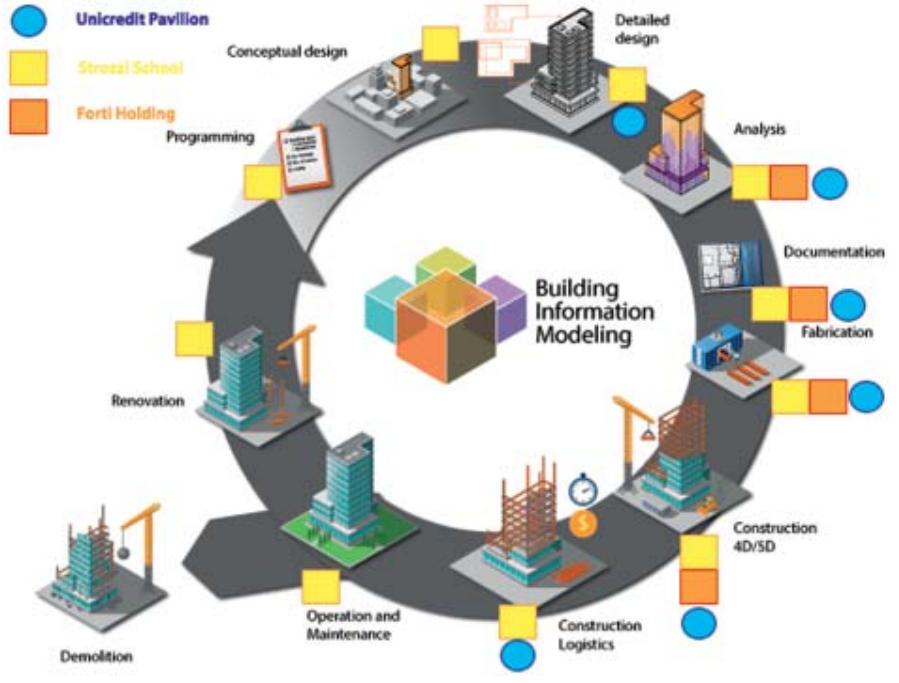

skills, as proved by the two projects of ATIproject, and this comes as a confirmation of In summary, we can confirm that the development of inno-

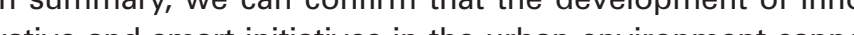
vaivs the adoption of new and less be applied wisely a $\mathrm{w}$ ithou forgeting to develop the skills tural and systems design.

BIBLIOGRAPHY

(BM in principle and in practice, ICE publishing, Londo, UK, 2014 . The impact of building information modelling: transforming constru-
crtion, Spon press, New York, USA, 2012. ill. 20: Summary of the presented projects aligned to
main phases of the design and construction process. (Elaboration by D. Duchev)

Duchev D, Design with BIM and the information systems,
Bachelor thesis, University supervisor: Prof. Elisabetta G Politecnico di Milano, Milano, IT 2015 .

Garber $R$, BIM DESIGN. Realising the creative potential
of building information modelling, Wiley, Chichester, $U$.

PERIODICS

World Green Building Trends 2016. Developing Markets accelerate Global Green Growth" in Smart Marke
Dodge DatafAnalytics, Bedford, MA, USA, 2016.

Report, McGraw Hill Construction, Bedford, MA. USA. 2014. "The Business Value of BIM for Construction in Major GIobal Markets" in Smart Market Report
ction, Bedford, MA, USA, 2014. 